This document is the preprint manuscript version of a published work that appeared in final form in Biomaterials, () 2019 Elsevier Ltd. after peer review and technical editing by the publisher. To access the final edited and published work see: https://doi.org/10.1016/j.biomaterials.2019.119657

\title{
Nose-to-brain delivery of enveloped RNA - cell permeating peptide nanocomplexes for the treatment of neurodegenerative diseases
}

\author{
Eleni Samaridou ${ }^{\mathrm{a}}$, Hannah Walgrave ${ }^{\mathrm{b}}$, Evgenia Salta $^{\mathrm{b}}$, David Moreira Álvarez ${ }^{\mathrm{c}}$, Vanessa Castro-López ${ }^{\mathrm{a}}$, \\ Mabel Loza ${ }^{c}$, Maria José Alonso ${ }^{\text {a* }}$
}

${ }^{\text {a }}$ Center for Research in Molecular Medicine and Chronic Diseases, IDIS research Institute, Department of Pharmacy and Pharmaceutical Technology, School of Pharmacy, Universidade de Santiago de Compostela, 15782, Santiago de Compostela, Spain.

${ }^{\mathrm{b}}$ Vlaams Instituut voor Biotechnologie (VIB) Center for Brain and Disease, VIB-Leuven, Leuven, Belgium; $\uparrow$ Center for Human Genetics, Universitaire Ziekenhuizen and Leuven Research Institute for Neuroscience and Disease, KULeuven, Leuven, Belgium

${ }^{\mathrm{c} B i o F a r m a ~ R e s e a r c h ~ G r o u p, ~ C I M U S, ~ U n i v e r s i d a d e ~ d e ~ S a n t i a g o ~ d e ~ C o m p o s t e l a, ~ S a n t i a g o ~ d e ~ C o m p o s t e l a, ~ S p a i n ~}$

* Corresponding author

Department of Pharmacy and Pharmaceutical Technology, Center for Research in Molecular Medicine and Chronic Diseases, IDIS research Institute, Universidade de Santiago de Compostela, 15782, Santiago de Compostela, Spain.

E-mail address: mariaj.alonso@usc.es (M.J. Alonso)

Keywords: Nose-to-Brain administration; Brain delivery; Nanocomplex; Cell-penetrating peptide; Octaarginine; miRNA 


\section{Abstract}

Direct nose-to-brain (N-to-B) delivery enables the rapid transport of drugs to the brain, while minimizing systemic exposure. The objective of this work was to engineer a nanocarrier intended to enhance N-to-B delivery of RNA and to explore its potential utility for the treatment of neurological disorders. Our approach involved the formation of electrostatically driven nanocomplexes between a hydrophobic derivative of octaarginine (r8), chemically conjugated with lauric acid (C12), and the RNA of interest. Subsequently, these cationic nanocomplexes were enveloped (enveloped nanocomplexes, ENCPs) with different protective polymers, i.e. polyethyleneglycol - polyglutamic acid (PEG-PGA) or hyaluronic acid (HA), intended to enhance their stability and mucodiffusion across the olfactory nasal mucosa. These rationally designed ENCPs were produced in bulk format and also using a microfluidics-based technique. This technique enabled the production of a scalable nanoformulation, exhibiting; (i) a unimodal size distribution with a tunable mean size, (ii) the capacity to highly associate $(100 \%)$ and protect RNA from degradation, (iii) the ability to preserve its physicochemical properties in biorelevant media and prevent the premature RNA release. Moreover, in vitro cell culture studies showed the capacity of ENCPs to interact and be efficiently taken-up by CHO cells. Finally, in vivo experiments in a mouse model of Alzheimer's disease provided evidence of a statistically significant increase of a potentially therapeutic miRNA mimic in the hippocampus area and its further effect on two mRNA targets, following its intranasal administration. Overall, these findings stress the value of the rational design of nanocarriers towards overcoming the biological barriers associated to N-to-B RNA delivery and reveal their potential value as therapeutic strategies in Alzheimer's disease. 


\section{Introduction}

Nowadays, with an ever-increasing ageing population worldwide, neurological disorders are continuously growing, resulting in the 12\% of global deaths [1]. Among these disorders, Alzheimer's disease constitutes the sixth leading cause of death, affecting nearly 44 million people worldwide [2]. However, despite the enormous efforts of the scientific community, the currently available therapeutic approaches offer only a mere alleviation of their pathological symptoms, and not a treatment against the actual cause of these diseases. As a disruptive alternative, the use of RNA interference (RNAi) - based therapeutics holds great promise to revolutionize the treatment of these debilitating disorders [3]. However, delivering therapeutic RNA molecules to the brain has been proven particularly challenging due to their lability, risk of off-target effects, immunogenicity and poor permeability through biological membranes [4-6]. In addition, the central nervous system (CNS) is tightly protected by the blood-brain barrier (BBB), which represents a major obstacle for the RNA delivery to the CNS [7]. This delivery problem explains the limited number of RNA-based formulations in the market or in advanced clinical phases for neurological indications (i.e., nusinersen (Spinraza), ATL1102, IONIS-SOD1 $1_{\mathrm{Rx}}$, IONIS-HTT $\left._{\mathrm{Rx}}\right)[7,8]$.

As an alternative, direct nose-to-brain (N-to-B) drug delivery has gained increasing interest, offering a bypass to the BBB through the olfactory epithelium [9-11]. However, overcoming this barrier also poses significant hurdles including the presence of digestive enzymes, protective mucus and a tidily organized epithelium $[12,13]$. Although in their early development stage, nanostructured delivery systems have been proposed as a strategy to facilitate the transport of RNA molecules to the brain via the nose. The knowledge generated so far has led to the conclusion that the size of the nanocarrier should be ideally $\leq 100 \mathrm{~nm}$ in order to be taken-up by the olfactory route, and the drug loading potency of the carrier must be very high, due to the limited volume to be administered intranasally $[12,13]$.

The main nose-to-brain delivery strategies explored so far have relied on the use of penetration enhancers [1420]. Among them, the so-called cell penetrating peptides (CPP) have attracted singular attention [21]. Recent studies have highlighted the potential of arginine (R)-rich peptides, like the trans-activated transcription (TAT) peptide $[14,15,17]$ or the RVG-9R, a 29-amino-acid peptide derived from the rabies virus glycoprotein (RVG) [20], to facilitate the delivery of siRNA to the brain of rodents, via the olfactory nerve pathway, for the treatment of neurodegenerative diseases. On the other hand, the hydrophobic modification of the CPPs, with either myristoyl, stearyl or lauryl lipid tails, has been found to increase their lipophilicity, and subsequently their stability and membrane penetration capacity [22-24]. Moreover, in a recent study, Kanazawa et al. studied the effect of hydrophobic modifications of the CPPs on their brain biodistribution, following their N-to-B administration to rats and showed that hydrophobically-modified CPPs exhibited a targeted transport of the associated drugs through the olfactory pathway to the forebrain [25]. 
On the basis of these premises, we disclose here a new delivery strategy that involves a combination of key components, which were specifically selected taking into account the biological barriers to be overcome for the efficient N-to-B RNA delivery. More precisely, the novelty of our approach relies on the formation of electrostatically driven nanocomplexes between a hydrophobic derivative of octaarginine (r8), chemically conjugated with lauric acid (C12), and the RNA of interest, and their subsequent envelopment with different protective biopolymers. Two different enveloping polymers were studied for their capacity to provide the CPPRNA nanocomplexes with an improved stability and a protection against the enzymes present in the olfactory area, the block copolymer of polyethylene glycol and polyglutamic acid (PEG-PGA) and hyaluronic acid (HA). These protective polymers were also expected to facilitate the diffusion of the complexed RNA across the mucus layer, overlaying the olfactory epithelium. Following the development of these nanostructures, here referred to as enveloped nanocomplexes (ENCPs), in bulk format, we optimized the formulation process of this system by using a microfluidic mixing system. The effect of different parameters on the properties of the produced NPs was examined. Furthermore, characterization of the resulting nanostructures included studying their ability to protect RNA from degradation, their colloidal stability and RNA release upon incubation with biorelevant media, their capacity to be uptaken in vitro, and finally their brain biodistribution and efficacy in vivo, following their intranasal administration to a mouse model of Alzheimer's disease.

\section{Materials and methods}

\subsection{Materials}

The transfer Ribonucleic acid (tRNA) from baker's yeast (S. cerevisiae), agarose (BioReagent, for molecular biology) with low electroendosmosis and heparin sodium salt from porcine intestinal mucosa (Grade I-A, $\geq 180$ USP units/mg) were all purchased from Sigma Aldrich (St. Luis, USA). miRIDIAN microRNA Human hsamiR-132-3p mimic (miR132 mimic) and negative control (scrambled miRNA) were procured by Dharmacon Inc. (GE Healthcare, Belgium). Lauryl acid coupled to the $N$-terminal of Octaarginine (D-type) (C12-r8, MW=1449.85 Da) was purchased from China Peptides (Shangai, China). Diblock pegylated polyglutamic acid or PEG-PGA (m[PEG] $]_{45}$-b-[PGA $]_{10}$, methoxy-poly(ethylene glycol)-block-poly(L-glutamic acid sodium salt), MW=22 kDa; $20 \mathrm{kDa}$ PEG and $2 \mathrm{kDa}$ PGA) was purchased from Polypeptide Therapeutic Solutions (PTS, Valencia, Spain). Sodium hyaluronic acid (HA) with average MW of $57 \mathrm{kDa}$ was purchased from LifeCore Biomedical. High glucose Dulbecco's modified eagle medium (DMEM) and non-essential amino acid (NEAA) solution were purchased from Sigma Aldrich (St. Louis, USA), while fetal bovine serum (FBS), penicillin-streptomycin solution, L-glutamine, phosphate-buffered saline (PBS), Dulbecco's phosphatebuffered saline with calcium and magnesium (DPBS) were purchased from Lonza (Basel, Switzerland). OptiMEM I Reduced Serum Media and Fetal Bovine Serum (FBS) was purchased from Gibco (Thermo Fisher 
Scientific Inc, California, USA). Quant-iT RiboGreen RNA assay kit (Molecular Probes) and ultraPure ${ }^{\mathrm{TM}}$ DNase/RNase-Free Distilled Water were obtained from Invitrogen (Thermo Fisher Scientific Inc, California, USA). Sucrose was purchased from Acofarma, whereas trehalose dihydrate, of high purity and low endotoxin, from Pfanstiehl, Inc. All other chemicals were of analytical grade.

\subsection{Preparation of the C12-r8-RNA Nanocomplexes (NCPs)}

To study the capacity of the hydrophobically modified octaarginine (C12-r8) to condense oppositely charged RNA molecules into nanosized complexes, we chose to use a transfer RNA (tRNA) from baker's yeast (Saccharomyces cerevisiae) as a model RNA. Nanocomplexes (NCPs) between C12-octaarginine (C12-r8) and the model tRNA were prepared upon adding the tRNA solution, at a fixed concentration of $100 \mu \mathrm{g} / \mathrm{mL}$, to equal volume solution of increasing C12-r8 concentrations in RNase free water, corresponding to increasing positive to negative (nitrogen/phosphate, N/P) charge ratios (i.e., 0.5:1, 1:1, 2:1, 4:1, 6:1, 8:1, 10:1), under mild magnetic stirring $(300 \mathrm{rpm})$ for $30 \mathrm{~s}$ and then incubated for $20 \mathrm{~min}$ at room temperature, prior to further modification. The $\mathrm{N} / \mathrm{P}$ charge ratios were calculated as the molar ratios of the cationic groups of $\mathrm{C} 12$-r8 versus the anionic charges of the oligonucleotides. For the in vitro and in vivo evaluation of the formulation, miR-132 mimic, a therapeutic miRNA mimic, or a non-specific/scramble miRNA oligonucleotide, were used instead of the model RNA molecule and were associated with the C12-r8, at the selected N/P charge ratio, following the same methodology.

\subsection{Preparation of the Enveloped C12-r8-RNA Nanocomplexes (ENCPs)}

The resulting cationic nanocomplexes, at the optimal charge ratio of C12-r8 to RNA, were next enveloped by two different anionic protective polymers; the diblock PEG-PGA copolymer or the hyaluronic acid (HA). Accordingly, $1 \mathrm{~mL}$ of the above prepared NCPs dispersion was added in the aqueous solution of the polymeric coatings in RNAse free water, under mild magnetic stirring (300 rpm) for $10 \mathrm{~min}$. In the case of PEG-PGA, $50 \mu \mathrm{L}$ aqueous solution of $1 \mathrm{mg} / \mathrm{mL}$ of PEG-PGA were used, whereas in the case of the HA $0.5 \mathrm{~mL} \mathrm{of} 1 \mathrm{mg} / \mathrm{mL}$.

\subsection{Physicochemical characterization and morphology of NCPs and ENCPs}

Physicochemical characterization of the NCPs and the ENCPs was accomplished using a Malvern Zeta-Sizer (NanoZS, ZEN 3600, Malvern Instruments, Worcestershire, UK) fitted with a red laser light beam at wavelength of $632.8 \mathrm{~nm}$ and a photodiode detector at a backward scattering angle of $173^{\circ}$. The mean diameter and PdI of the nanocomplexes were determined using Dynamic Light Scattering (DLS), whereas the Zpotential was calculated from the mean electrophoretic mobility values, determined by Laser Doppler Anemometry (LDA), using the same device, following a two times dilution in water. Analysis of the size 
distribution and concentration of the ENCPs was also performed using Nanoparticle Tracking Analysis (Nanosight NS300, Malvern Instruments, Worcestershire, UK), following their 200-fold dilution in water. The morphological analysis of the NCPs and ENCPs was carried out using a field emission scanning electron microscope (FESEM, ultra plus, Zeiss, Germany). Briefly, $5 \mu \mathrm{L}$ of the sample were left to dry onto the surface of silicon wafers overnight, which were then subjected to sputter coating of $10 \mathrm{~nm}$ of iridium with Quorum iridium sputter coater (Q150T, Quorum technologies, U.K.), prior to observation.

\subsection{Evaluation of RNA association efficiency}

The complexation of RNA in the case of NCPs, as well as in the case of the ENCPs was evaluated both qualitatively and quantitatively. As a first step, the association of the RNA was evaluated qualitatively by a gel mobility assay using agarose gel electrophoresis. Briefly, mixtures of $23.5 \mu \mathrm{L}$ of the nanocomplexes suspension (containing $\sim 0.7-1 \mu \mathrm{g}$ of RNA), $6 \mu \mathrm{L}$ of glycerol and $0.5 \mu \mathrm{L}$ of Sybr gold stain were loaded in the wells of $1 \%$ agarose gel. The electrophoresis was carried out at $100 \mathrm{~V}$, in Tris acetate-EDTA (TAE) running buffer, for 10 min. RNA was visualized with a UV lamp using a Trans-illuminator imaging system (Molecular Imager ${ }^{\circledR}$ Gel Doc $^{\mathrm{TM}}$ XR+ System with Image Lab ${ }^{\mathrm{TM}}$ Software, Biorad, California, USA). The presence of RNA in the formulation was also confirmed by its displacement using the polyanion heparin, prior to the gel electrophoresis. To ensure complete RNA release, aqueous solution of heparin was added to the nanocomplexes, at a mass ratio of heparin to RNA equal to $20: 1$, and left to incubate for $15 \mathrm{~min}$ at $37^{\circ} \mathrm{C}$. The RNA association efficiency in the case of the ENCPs was further quantified using a RiboGreen ${ }^{\mathrm{TM}}$ fluorescent stain assay, both by an indirect and direct method, in the absence and presence of $0.025 \%$ SDS respectively. For the quantification of the unbound RNA, samples were diluted 100-fold in TE buffer (1x), whereas for the direct determination of the total RNA associated in the formulation, they were first dissolved by adding equal volume of $0.5 \%$ SDS to achieve complete RNA release and then diluted 100 -fold in water, before reacting with Ribogreen reagent. Following the manufacturer instructions, the RiboGreen reagent was diluted 200 times in TE buffer and added to an equal volume of sample (total volume $200 \mu \mathrm{L}$ ). Samples were incubated for 5 min at room temperature in 96-well black polystyrene microplate (Corning ${ }^{\circledR}, \mathrm{New}$ York, USA) before measuring their fluorescence intensity, using a microplate reader (Synergy H1, BioTek Instruments, Vermont, USA) (excitation/emission $=495 / 525 \mathrm{~nm})$. RNA standard curves were prepared in TE $(1 \mathrm{x})$, but also in the presence of SDS $0.025 \%$, in the range of $0.02-1.0 \mu \mathrm{g} / \mathrm{mL}$. As additional controls, the calibration curve of RNA was performed in the presence of all the components to exclude any potential interference, and the free RNA was also quantified, following its separation from the formulation by ultrafiltration (Nanosep® Centrifugal Devices, 300 kDa cut-off, Omega ${ }^{\mathrm{TM}}$, Pall Corporation, New York, USA). 


\subsection{Colloidal stability and RNA protection in biorelevant conditions}

The colloidal stability of the ENCPs was assessed upon incubation of the ENCPs in equal volume of phosphate buffered saline (PBS, 1x, pH 7.0) containing 10\% FBS, simulating the physiologic $\mathrm{pH}$ at the olfactory area, at a RNA concentration of 16.5 and $23.5 \mu \mathrm{g} / \mathrm{mL}$, respectively. The mixtures were incubated at $37{ }^{\circ} \mathrm{C}$ with a horizontal shaking of $300 \mathrm{rpm}$, for different time periods up to 24 hours $(0,0.5,1,2,4,6,8$ and $24 \mathrm{~h})$ at which a $50 \mu \mathrm{L}$ sample of the mixture was withdrawn in order to analyze the particle size, as described above. To address the capacity of the ENCPs to protect their RNA load in the presence of enzymes, the samples were subsequently electrophoresed in a $1 \%$ agarose gel. Naked RNA treated under the same conditions was used as control. To be able to visualize the intact, unreleased RNA under these conditions, $20 \mu \mathrm{L}$ of the mixtures were treated with $12 \mu \mathrm{L}$ of heparin aqueous solution $(1.25 \mathrm{mg} / \mathrm{mL})$, and left to incubate for $10 \mathrm{~min}$ at $37^{\circ} \mathrm{C}$, prior to their electrophoresis.

\subsection{Stability of the ENCPs upon storage}

The storage stability of the enveloped systems was studied at $4{ }^{\circ} \mathrm{C}$ and at room temperature $\left(25^{\circ} \mathrm{C}\right)$. The ENCPs suspensions were stored under these conditions for up to 1 month. Weekly measurements of the particle size, PDI and derived count rate (dCR) were carried out as described above. Furthermore, freshly prepared nanocomplexes were lyophilized in the presence of cryoprotectants, such as sucrose and trehalose at two different concentrations; 2 and $5 \% \mathrm{w} / \mathrm{v}$, to assess the possibility of processing them as a powder. Freeze drying ( $\sim 50 \mathrm{~h}$ cycle) was performed using the Genesis VirTis 25EL Pilot Lyophilizer (SP Scientific, USA). The dried samples were resuspended in water and characterized by dynamic light scattering.

\subsection{Microfluidic-based preparation of NCPs and ENCPs}

Following the development and optimization of NCPs and ENCPs with a model RNA molecule in bulk format, we then proceeded to explore the possibility of a robust and scalable manufacturing of this type of nanocarriers, using a microfluidic mixing system (NanoAssemblr ${ }^{\mathrm{TM}}$ bench-top instrument, Precision NanoSystems, Inc., Vancouver, Canada) [26]. This microfluidic device is based on the use of cartridge-like micromixers with herringbone structures, having two distinct inlet channels (width: $200 \mu \mathrm{m}$, height: $79 \mu \mathrm{m}$ ), connected with a dual syringe pump, which controls the flow rate and flow rate ratios through the device, and one outlet channel. This setup enables a straight-forward scale-up of the formulations by the simple parallelization of these micromixers. The method, developed here for the preparation of PEG-PGA or HA enveloped ENCPs, replicated the stepwise assembly process used in bulk mixing by allowing the RNA and C12-r8 to yield first C12-r8 - RNA nanocomplexes, before adding the polymeric coating to consolidate the initially formed complexes. Accordingly, to generate the C12-r8-RNA NCPs, equal volumes of C12-D-r8 (0.22 mg/mL) and 
RNA $(0.1 \mathrm{mg} / \mathrm{mL})$ aqueous solutions were added to the respective channels of the micromixer and were rapidly mixed under a total flow rate of $8 \mathrm{ml} / \mathrm{min}$, with a flow rate ratio between the two channels equal to $1: 1$. The microfluidic produced nanocomplexes were characterized in terms of particle size, z-potential and the ability to associate RNA, as briefly described above. To further generate PEG-PGA or HA enveloped NCPs, $1 \mathrm{~mL}$ of the dispersion of the previously prepared C12-r8 - RNA nanocomplexes was added again to the respective micromixer channel and rapidly mixed with $0.5 \mathrm{~mL}$ of an aqueous solution of the polymeric coating (1 $\mathrm{mg} / \mathrm{mL}$ ), under a total flow rate of $8 \mathrm{ml} / \mathrm{min}$ and a flow rate ratio of coating to NCPs channels, equal to 2:1. The characterization of the microfluidic produced ENCPs was performed as described above.

\subsection{Cellular internalization studies}

To study the capacity of the ENCPs to be taken-up by cells in vitro, $\mathrm{CHO}$ cell line (obtained from ATCC) was cultured in DMEM F-12, complemented with $10 \%$ FBS and $100 \mathrm{U} / \mathrm{ml}$ of penicillin/streptomycin. Cells were kept at $5 \% \mathrm{CO}_{2}$ incubator at $37^{\circ} \mathrm{C}$. 24 hours before the study, 225,000 $\mathrm{CHO}$ cells were seeded per well (six replicates) in 6-well plates to reach $40-50 \%$ confluence. The next day, the cells were incubated with the miR132 loaded ENCPs or miR-132 complexed with lipofectamine RNAiMAX (at 1:1 volume ratio) as a control, at a final concentration of $400 \mathrm{nM}$ in OPTIMEM (replacing the cell medium) for 4 hours at $5 \% \mathrm{CO} 2$ and $37^{\circ} \mathrm{C}$. The cells were then washed with PBS twice, trypsinized, harvested and frozen at $-80^{\circ} \mathrm{C}$ until further processed. miRNA was isolated from $\mathrm{CHO}$ cells using mirVana ${ }^{\mathrm{TM}}$ miRNA Isolation Kit (Ambion by Life Technologies) according to the manufacturer's instructions. Reverse transcription of $10 \mathrm{ng}$ miRNA for each sample was performed using the miRCURY LNA RT Kit (Quiagen) according to the manufacturer's protocol. Real-time semi-quantitative PCR was performed using the miRCURY LNA SYBR Green PCR Kit (Quiagen) and LNA PCR miRNA 132, U6 and miRNU5G primers (Exiqon) in a Quantstudio 12k Flex Applied Biosystems Cycler (Life Technologies), as described below.

\subsection{Animal procedures}

All animal experiments were carried out in accordance to institutional guidelines, approved by the ethical committees of KU Leuven and UZ Leuven. In this study, App ${ }^{\text {NL-G-F }}$ knock-in mouse model of Alzheimer's disease was used. Food and water were provided ad libitum. This AD mouse model carries a humanized A $\beta$ precursor protein (APP) sequence with Swedish (NL), Arctic (G) and Iberian (F) mutations, resulting in memory deficits and widespread distribution of amyloid plaques [27].

\subsection{In vivo brain distribution following N-to-B administration}

To first evaluate the overexpression and brain distribution of the therapeutic miRNA in vivo, 11-month old 
male APP ${ }^{\mathrm{NL}-\mathrm{G}-\mathrm{F}}$ mice were administered intranasally a single dose of $6.5 \mathrm{nmol}$ of miR-132 mimic or negative control oligonucleotide loaded ENCPs. The administration was performed using a micropipette (Eppendorf P20) at a rate of $4 \mu \mathrm{L}$ per nostril, with a hold time of 2 minutes between each dose to allow the animal to breathe normally and snort the administered drop. The mice were sacrificed at 24 hours post dosing and their whole brain was collected ( $n=3$ for control and $n=4$ for miR-132). The olfactory area, hippocampus and posterior cortex were then microdissected, snap frozen and stored at $-80^{\circ} \mathrm{C}$ until further processing. miRNA was isolated, according to the protocol described below, and the miR-132 was quantified by semi-quantitative real-time PCR analysis in comparison to the control-dosed animals (negative control miRNA loaded ENCPs).

\subsection{In vivo efficacy following N-to-B administration}

To study the interaction of the miR-132 loaded ENCPs with potential mRNA targets in vivo, as identified by Salta et al. before [28], APP ${ }^{\mathrm{NL}-\mathrm{G}-\mathrm{F}}$ mice received 3 intranasal doses of $5 \mathrm{nmol}$ miRNA or control oligonucleotide each with a two hour interval between doses, using the same methodology as before. The total miR-132 dose administered to each mouse was $15 \mathrm{nmol}$. Control mice received negative control miRNA loaded ENCPs. Twelve hours after the last dosing, the animals were sacrificed by cervical dislocation and the whole brain was collected from each animal. The hippocampus was chosen as the brain area of interest for Alzheimer's disease and was then microdissected, snap frozen and stored at $-80^{\circ} \mathrm{C}$ until further processing. The miRNA and mRNA levels of miR-132 targets were assessed by semi-quantitative real-time PCR analysis, according to the protocol described below.

\subsection{RNA isolation, reverse transcription, and real-time PCR}

For RNA analysis, hippocampi were processed using the miRVana Paris Kit (Life Technologies, Belgium) according to the manufacturer's instructions. Briefly, tissue was homogenized (or cells were lysed) in cell disruption buffer supplemented with protease and phosphatase inhibitors. Following denaturation, addition of acid phenol:chloroform, incubation, and centrifugation, 1.25 volumes of ethanol $100 \%$ were added to the aqueous phase. The samples were then loaded on miRVana spin columns and processed according to the manufacturer's instructions. Reverse transcription of mRNA or miRNA was performed using the Superscript II reverse transcriptase (Invitrogen, Life Technologies Europe, Belgium) for protein-coding transcripts and the Universal cDNA synthesis kit (Exiqon, Denmark) for miRNAs. Real-time semi-quantitative PCR was performed using the LightCycler 480 Sybr Green (Roche Diagnostics, Belgium) for coding transcripts and the Sybr Green mastermix and LNA PCR primers (Exiqon, Denmark) for miRNAs. The primer sequences have been described previously by Salta et al. [28]. Fold changes were calculated with the $\Delta \Delta C t$ method, as described before [29]. 


\subsection{Statistical analysis}

All the data were expressed as mean \pm standard deviation (SD) unless otherwise indicated. Differences between multiple groups were analyzed using one-way ANOVA followed by Tukey test. A paired t-test was used to determine if there was a statistically significant change in the levels of miR-132 or in the levels of its mRNA targets in the hippocampus and olfactory bulb areas following the intranasal administration of miR-132 loaded ENCPs. Statistical significance was defined as $\mathrm{p}<0.05$. Calculations were performed using GraphPad Prism version 5.00 for Windows.

\section{Results and discussion}

The present study aimed at designing an innovative 'nose-to-brain' RNAi delivery strategy to be used for treatment of neurodegenerative diseases. To that end, we engineered a nanocarrier intended to transport RNAi molecules from the nose directly to the brain. This design involved the formation of core-shell nanoparticles, where the nanoparticle core contained a modified CPP complexed to the RNA molecule of interest and, the shell, made of PGA-PEG or hyaluronic acid, had a protective role against enzymatic degradation. To prove the potential of this rationally designed system against neurodegenerative diseases, we investigated its capacity to deliver a specific miRNA mimic, miR-132, with a reported therapeutic action in Alzheimer's disease (AD). miR-132 is consistently downregulated in human AD brain [28,30] and, hence, it has been suggested that restoring miR-132 levels (by using a miRNA mimic) could represent a novel therapeutic target in AD [28,31$34]$.

\subsection{Development and physicochemical characterization of the C12-r8-RNA Nanocomplexes (NCPs)}

The formation of nanocomplexes between C12-r8 and RNA, based on the electrostatic interaction between their amine and phosphate groups, respectively, was studied using transfer tRNA (tRNA), a short, non-coding, single-stranded RNA molecule as a model RNA molecule. To establish the optimal charge ratio of the C12-r8 to RNA, increasing concentrations of C12-r8 were mixed with a fixed concentration of tRNA, corresponding to N/P charge ratios from 0.5:1 up to 10:1, and their resulted complexes were studied in regards to their particle

size, charge and RNA association efficiency. The results of this screening indicated that, C12-r8 could successfully condense the RNA molecules at N/P charge ratios above 4:1.[35,36] The resulting complexes exhibited a nanometric size of around $69 \mathrm{~nm}$ and a positive surface charge, an indication of the complete 
condensation of RNA (Fig. 1A\&B). As expected, this positive surface charge of the nanocomplexes increased, with increasing N/P charge ratios above 4:1 (Fig. 1A\&B).
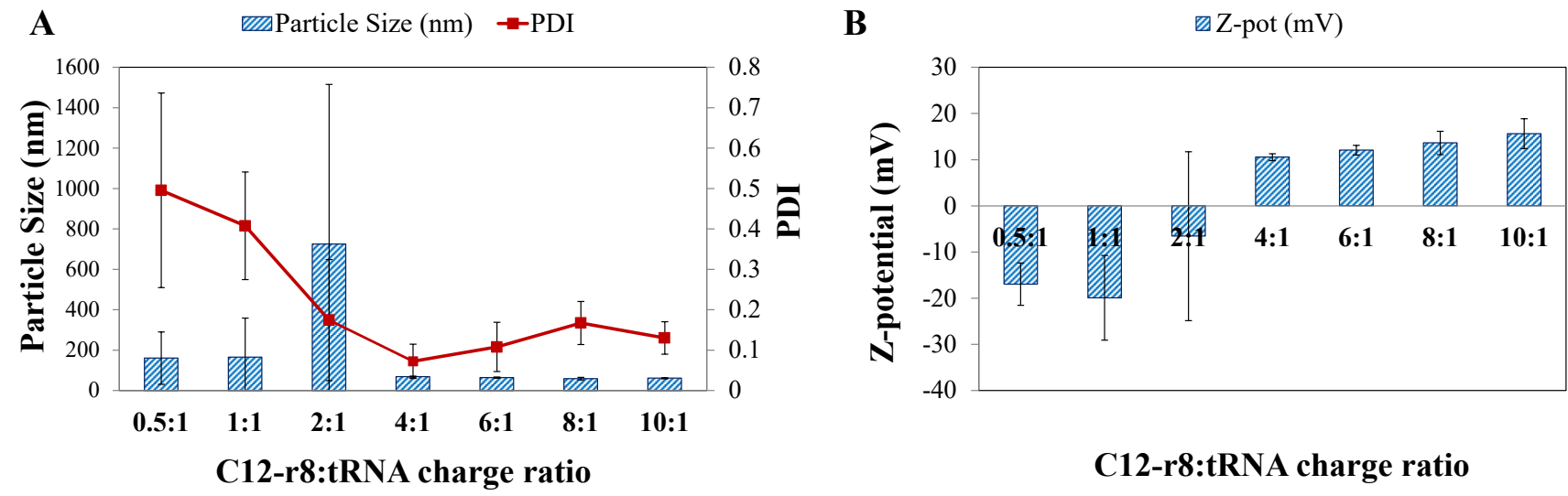

\section{C12-r8:tRNA charge ratio}

C

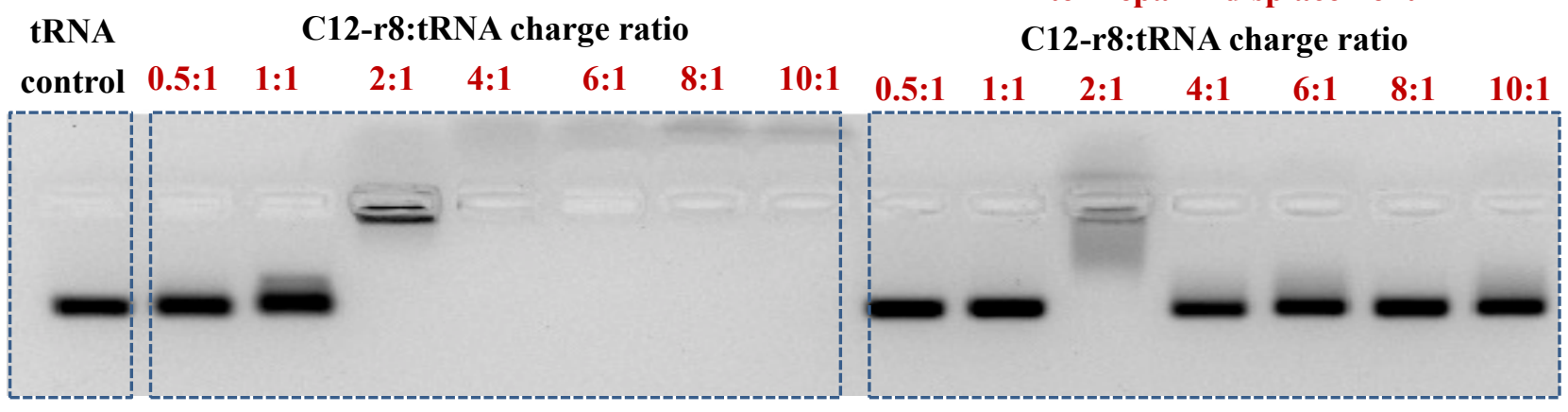

Figure 1. (A) Particle size, PDI and (B) z-potential of the nanocomplexes between C12-r8 and tRNA at different N/P charge ratios, ranging from 0.5:1 up to 10:1. (C) Agarose gel retardation assay indicating the RNA association efficiency of C12-r8/tRNA nanocomplexes at different N/P charge ratios, ranging from 0.5:1 to 10:1; Lane 1 is the naked tRNA (control), Lanes $2-8$ are NCPs at the respective N/P charge ratios, Lanes 9 - 15 are the NCPs at the respective charge ratios, following RNA displacement by heparin (mass ratio heparin: tRNA $=20: 1$ ). Data are expressed as mean $\pm \mathrm{SD}$, $\mathrm{n}>3$.

The C12-r8-RNA nanocomplexes were then subjected to agarose gel electrophoresis to examine the RNA binding efficiency. The results in Fig. $1 \mathrm{C}$ indicated that, as expected, RNA was fully condensed at ratios higher than $4: 1$, since the mobility of the tRNA was retarded, and the RNA staining hindered at these charge ratios ( Fig. 1C, Lanes 1-8). This was further confirmed by RNA displacement after incubating the nanocomplexes with heparin (Fig. 1C, Lanes 9-15). These data suggest that the RNA association efficiency was $\sim 100 \%$ at N/P charge ratio equal or higher than $4: 1$.

An objective of this work was to produce nanoparticles with a size of around $100 \mathrm{~nm}$ in order to facilitate their transport through the olfactory epithelium. For this reason, the N/P ratio 4:1, which resulted to reproducible, 
positively charged, nanosized complexes, with an 100\% RNA association efficiency, was selected as optimal and was used for further characterization and modification. Table 1 summarizes the physicochemical properties of the C12-r8:tRNA nanocomplexes at the optimal N/P charge ratio of 4:1 (n>3).

Table 1. Physicochemical properties of the C12-r8:tRNA nanocomplexes at N/P charge ratio $=4: 1$. Data are expressed as mean $\pm \mathrm{SD}, \mathrm{n}>3$.

\begin{tabular}{c|c|c|c|c}
\hline N/P Charge ratio & Av. Diam. (nm) & PDI & Z-pot (mV) & A.E. (\%) \\
\hline $4: 1$ & $69 \pm 3.0$ & 0.07 & $11.0 \pm 0.9$ & $\sim 100 \pm 0$ \\
\hline
\end{tabular}

\subsection{Development and physicochemical characterization of the Enveloped C12-r8-RNA Nanocomplexes (ENCPs)}

Generally, nanocomplexes based on the ionic interaction of polynucleotides and cationic polymer are not stable in biorelevant conditions. This was also the case of the C12-r8:tRNA complexes, which were found to be unable to protect the associated RNA in PBS containing FBS (data not shown). To improve their stability, the positively charged nanocomplexes $(\mathrm{N} / \mathrm{P}$ ratio $=4: 1)$ were enveloped by negatively charged protective polymers, pegylated polyglutamic acid (PEG-PGA) or hyaluronic acid (HA), leading to the formation of ENCPs. These two polymers were selected based on their favorable attributes, which are, apart from their neutral/negative charge, their well-known safety profile. The ENCPs showed unimodal nanometric sizes of around $96 \mathrm{~nm}$ and neutral z-potential, due to the presence of the PEG chains on their surface, whereas the HA coated nanocomplexes had a size of $106 \mathrm{~nm}$ and a negative neutral z-potential of -24 mV (Fig. 2F). The shielding of the positive surface charge of the initial nanocomplexes between C12-r8 and RNA was indicative of the successful envelopment of the nanocomplexes with the two polymers. In addition, the agarose gel electrophoresis results, prior and after the RNA displacement with heparin, allowed us to confirm that RNA remained fully associated to the nanocomplexes after the envelopment process (Fig. 2). This high RNA binding was confirmed, both directly and indirectly, using the RiboGreen ${ }^{\mathrm{TM}}$ fluorescent stain prior and after its displacement by SDS. ENCPs were also prepared using miR-132 mimic, a therapeutic miRNA mimic (or a non-specific/scramble miRNA oligonucleotide), instead of the model RNA molecule, following the same methodology, resulting in similar characteristics.

The size distribution and morphology of the enveloped nanocomplexes were also evaluated using NTA and FE-SEM analysis, respectively. Both techniques confirmed the monodispersity of the particles, with sizes $\leq 100$ $\mathrm{nm}$ and regularly spherical nanostructures for both coatings (Fig. 2B-E). 
A

After heparin displacement

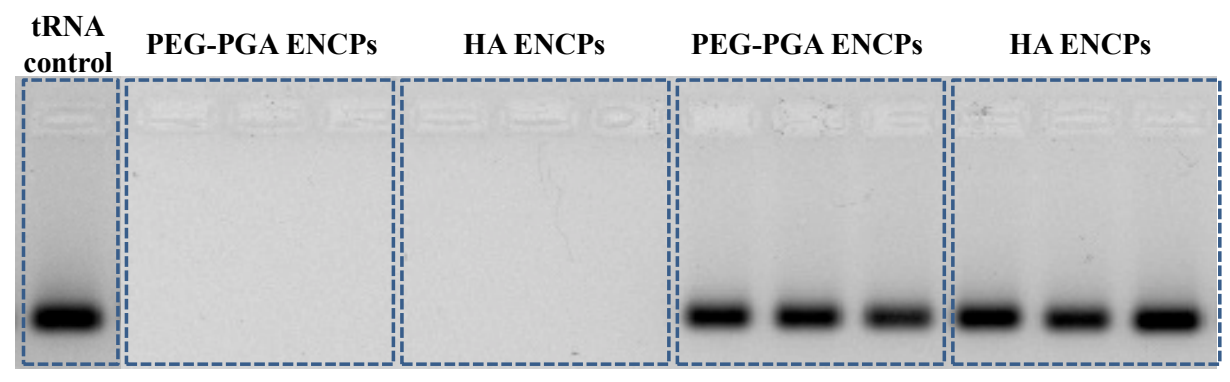

B

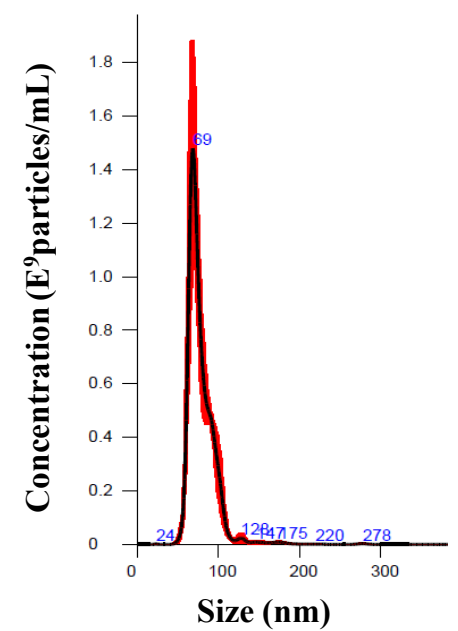

D

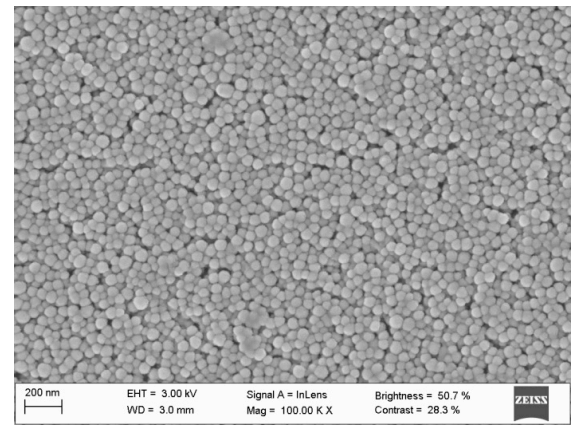

C

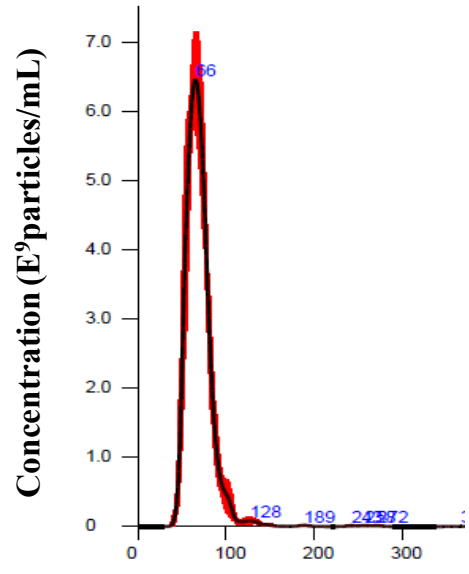

Size (nm)

$\mathbf{E}$

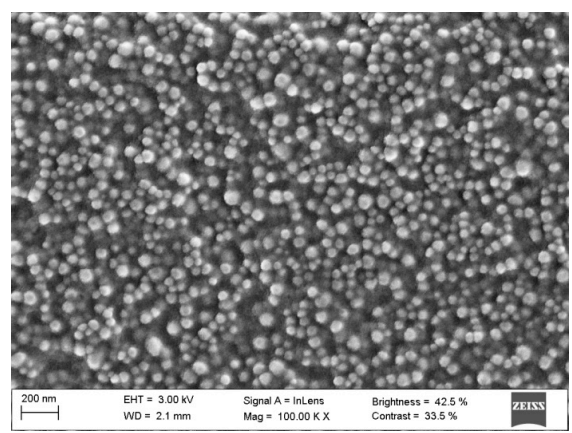

$\mathbf{F}$

\begin{tabular}{c|c|c|c|c}
\hline Nanocomplexes & Av. Diam. (nm) & PDI & Z-pot (mV) & A.E. (\%) \\
\hline PEG-PGA enveloped ENCPs & $96 \pm 17$ & 0.06 & $+4 \pm 1$ & $98.7 \pm 0.08$ \\
\hline HA enveloped ENCPs & $106 \pm 17$ & 0.1 & $-24 \pm 4$ & $96.8 \pm 0.05$ \\
\hline
\end{tabular}

Figure 2. (A) Agarose gel electrophoresis showing the RNA association efficiency of ENCPs; Lane 1 is the naked tRNA (control); Lanes 2 - 4 are PGA-PEG coated ENCPs $(n=3)$; Lanes 8-10 are HA coated ENCPs (n=3); whereas Lanes 5-7 and Lanes 10-12 are the respective ENCPs after incubation with heparin $\left(\mathrm{m}_{\mathrm{RNA}} / \mathrm{m}_{\mathrm{HEPARIN}}=1 / 20\right)$. (B) NTA analysis of the PEG-PGA and (C) HA enveloped nanocomplexes. Data are expressed as mean \pm SD, $n>3$. (D) FESEM morphology of the PEG-PGA and (E) HA enveloped nanocomplexes. (F) Physicochemical properties of Enveloped nanocomplexes (ENCPs) with C12r8:tRNA charge ratio of 4:1. Data are expressed as mean $\pm \mathrm{SD}, \mathrm{n}>3$. 


\subsection{RNA protection in the presence of enzymes}

One of the major limitations of RNA-based therapeutics is their predisposition to rapid enzymatic degradation in vivo. In addition, a concern when using electrostatically driven nanocomplexes is their stability in saltcontaining environment. It has been reported that the presence of salts can weaken the strength of complex formation, owing to the presence of oppositely charged ions, leading to swelling or aggregation, and eventually dissociation of the nanocomplexes and premature release of their therapeutic load. To assess the benefit of the nanocomplexes's envelop, their ability to protect the RNA was studied following their incubation in PBS containing $10 \% \mathrm{FBS}$ at $37{ }^{\circ} \mathrm{C}[37,38]$. The results in Figure 3 indicate that while naked RNA was fully degraded within minutes (Fig. 3, Lane 2) both, PEG-PGA and HA coatings could prevent the enzymatic degradation of the complexed RNA, possibly due to the steric blockage of these hydrolytic enzymes (Fig. 3). These results indicated the ability of the carriers to protect the RNA cargo and prevent its premature release in the presence of both enzymes and ions.

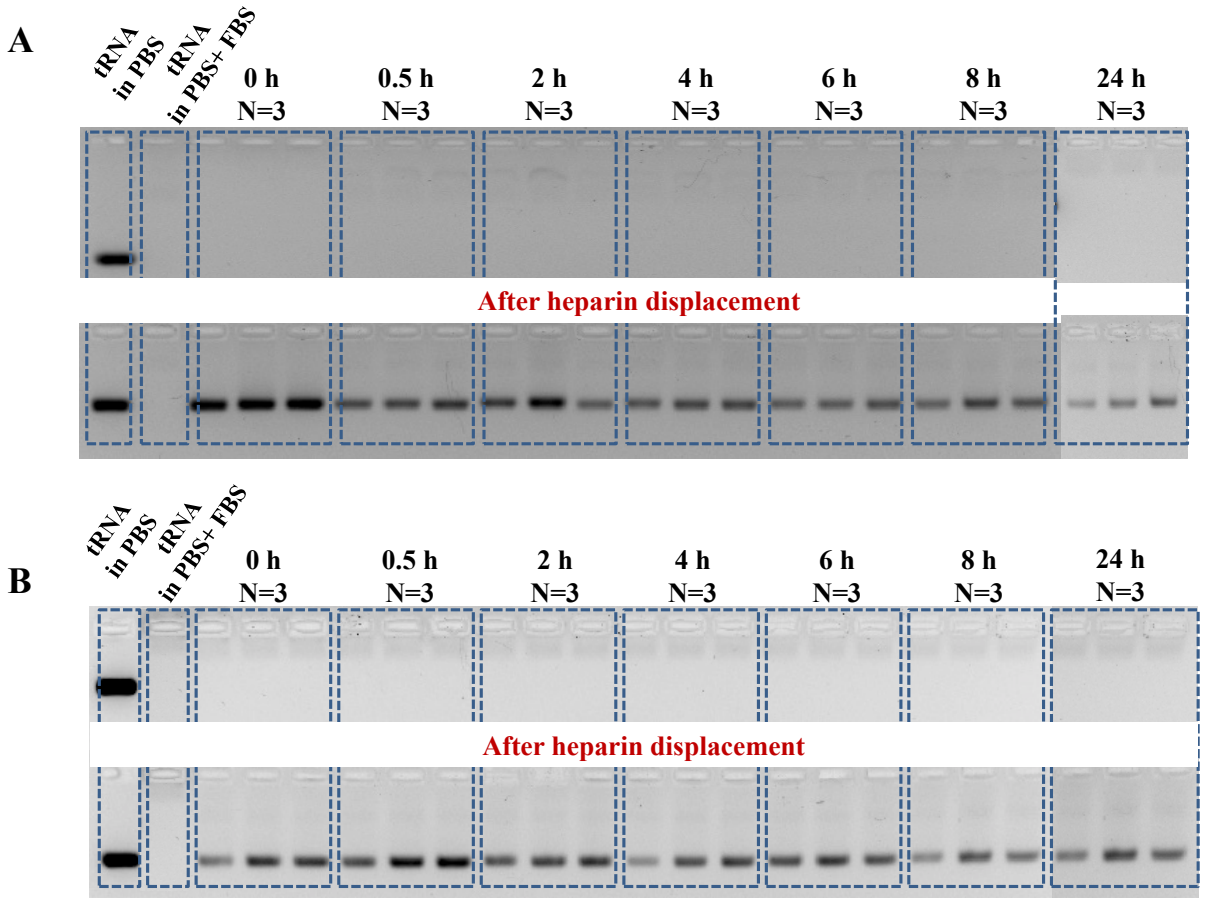

Figure 3. tRNA release from (A) PEG-PGA and (B) HA enveloped ENCPs upon incubation in PBS containing $10 \%$ FBS at $37^{\circ} \mathrm{C}$ for up to $24 \mathrm{~h}$. Upper line: Lane 1 is the naked tRNA in PBS (control); Lane 2 is the naked tRNA in PBS containing $10 \%$ FBS (control); Lanes 3 - 23 are ENCPs ( $\mathrm{n}=3$ ) at specific time points up to $24 \mathrm{~h}$ incubation at $37^{\circ} \mathrm{C}$ in PBS containing $10 \%$ FBS. Bottom line: Lanes 1-23 are the respective samples after RNA displacement with heparin (mRNA/mHEPARIN=1/20). 


\subsection{Stability of the Enveloped Nanocomplexes (ENCPs) upon storage and development of a freeze-dried}

formulation

The particle size, derived count rate (DCR) and RNA loading of the ENCPs were studied weekly to evaluate the stability of the ENCPs upon storage at 4 and $25^{\circ} \mathrm{C}$ for up to 1 month. The DCR is a relative parameter, used to compare the signal between different samples and to indicate variations in the concentration or the size of the particles in the dispersion. As presented in Fig. 4A-D, the enveloped systems retained their physicochemical characteristics and RNA loading under the mentioned storage conditions for at least 1 month. 
A
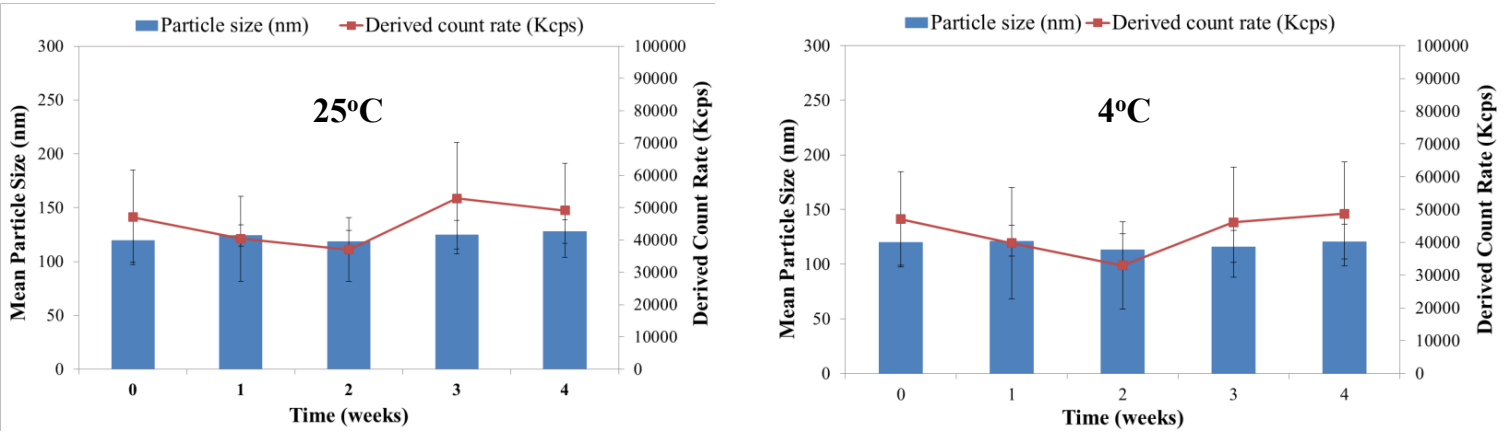

B
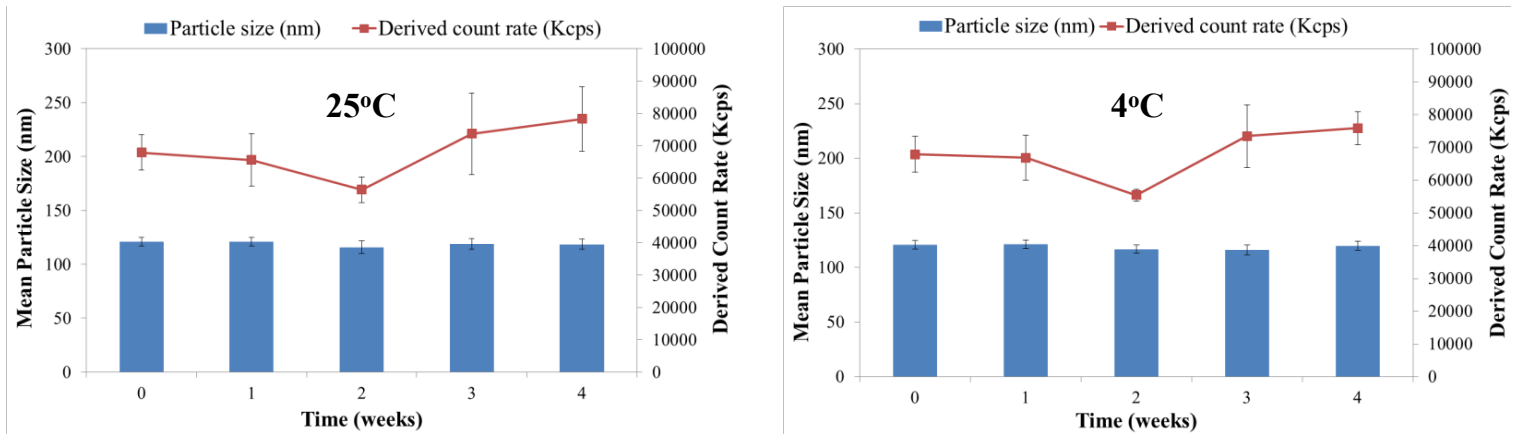

C
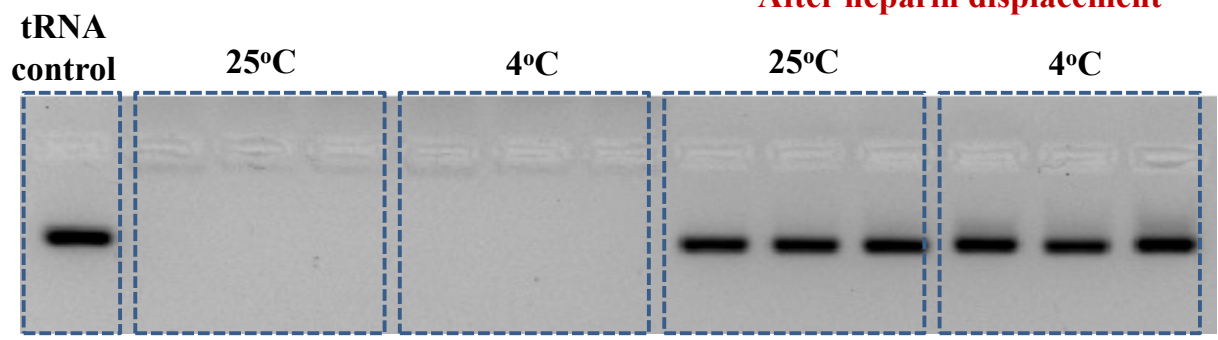

D

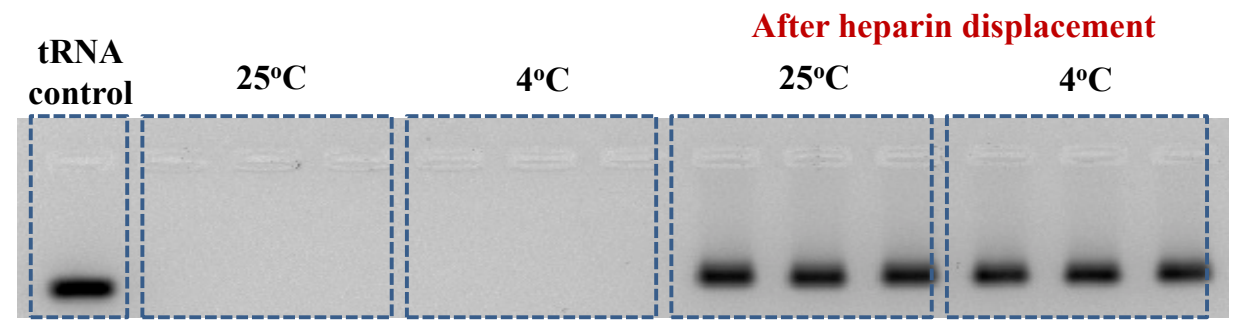

Figure 4. Stability studies in terms of particle size and DCR of (A) PGA-PEG and (B) HA enveloped nanocomplexes in terms of Particle size and Derived count rate under storage at $25^{\circ} \mathrm{C}$ and $4^{\circ} \mathrm{C}$ for up to 4 weeks. Data are expressed as mean $\pm \mathrm{SD}, \mathrm{n}=3$. Stability studies of (C) PGA-PEG and (D) HA coated ENCPs in terms of RNA association efficiency upon storage at $25^{\circ} \mathrm{C}$ and $4{ }^{\circ} \mathrm{C}$ for 4 weeks. Agarose gel electrophoresis; Lane 1 is the naked tRNA (control); Lanes 2 4 are ENCPs $(n=3)$ after storage at $25^{\circ} \mathrm{C}$ for 4 weeks; Lanes $5-7$ are ENCPs $(n=3)$ after storage at $4{ }^{\circ} \mathrm{C}$ for 4 weeks; Lane 8-13 are the respective ENCPs $(n=3)$, after incubation with heparin $(\mathrm{mRNA} / \mathrm{mHEPARIN}=1 / 20)$.

On the other hand, in order to explore the possibility of storing the ENCPs in powder form, freshly prepared 
nanocomplexes were lyophilized in the presence of cryoprotectants, such as sucrose and trehalose at two different concentrations; 2 and $5 \% \mathrm{w} / \mathrm{v}$. As the results indicated, trehalose at a concentration of 5\% was the best suited cryoprotective agent during freeze-drying, since the ENCPs mantained their mean particle size and derived count rate, following their reconstitution (Fig. 5).

A

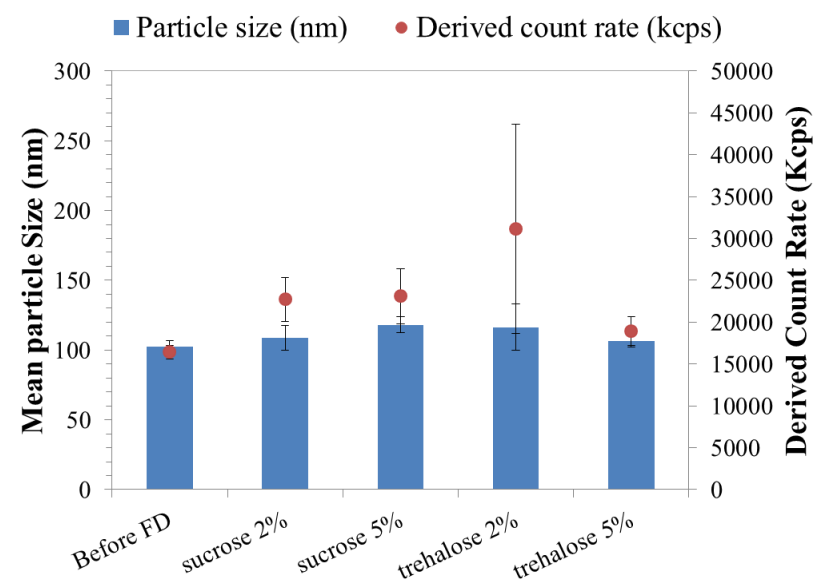

B

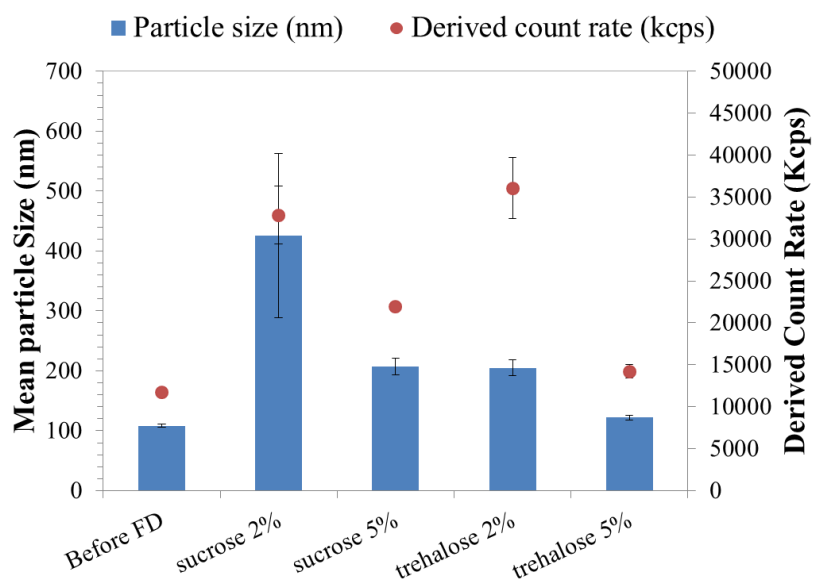

Figure 5. Mean particle size and Derived count rate of (A) PGA-PEG and (B) HA coated ENCPs before and after freezedrying in the presence of different cryoprotectants (mean $\pm \mathrm{SD} ; \mathrm{n}=3$ ). (FD; Freeze Drying)

\subsection{Microfluidic-based preparation of NCPs and ENCPs}

Following the development and characterization of ENCPs with a model RNA molecule in bulk format, we proceeded to manufacture these systems, using a cartridge-based microfluidic mixing system. Microfluidic manufacture offers several advantages over classical bulk methods, such as, higher control over mixing profile and reaction time of the components, user-independent production, ensured reproducibility, scalability and potential for mass production [39]. For this reason, PEG-PGA, as well as HA enveloped ENCPs were manufactured using a staggered herringbone micromixer (SHM) (NanoAssemblr ${ }^{\mathrm{TM}}$ bench-top, Precision NanoSystems, Inc., Vancouver, Canada), mimicking the stepwise assembly process used in bulk mixing. The SHM, used here, enables the repeated rapid mixing of the two streams, thus leading to an increase in the surface area of the interface, a reduction in the diffusional distance and, ultimately, in an optimal mixing [40]. Moreover, this equipment allows the scale up production by the simple parallelization of micromixers [41].

As a first step, the formation of C12-r8- RNA NCPs was studied in order to find the optimal conditions for their preparation. For that, a $3^{2}$ full factorial design was performed aiming to evaluate the effect of different parameters, i.e. the flow rate ratio of the two streams and the concentration of octaarginine, on the properties 
of the resulted NCPs. The effect of the flow rate had been evaluated before, showing no effect on the properties of the NCPs and for that reason it was kept steady at $8 \mathrm{ml} / \mathrm{min}$ (data not shown). Based on this screening, we concluded that increasing the concentration of the C12-r8 or the flow rate ratio of C12-r8:RNA, resulted in a decrease in the nanocomplex size and PDI, and at the same time an increase in the RNA AE and z-pot of the formulations (Fig. 6). Accordingly, microfluidic mixing of C12-r8 and tRNA aqueous solutions at flow rate ratio $(\mathrm{FRR})=1: 1$ and concentration of $\mathrm{C} 12-\mathrm{r} 8$ equal to $0.22 \mathrm{mg} / \mathrm{ml}$, enabled the rapid and consistent manufacturing of NCPs having diameters of around $70 \mathrm{~nm}$, a surface charge of $12 \mathrm{mV}$ and an $\sim 100 \%$ RNA association efficiency.

A

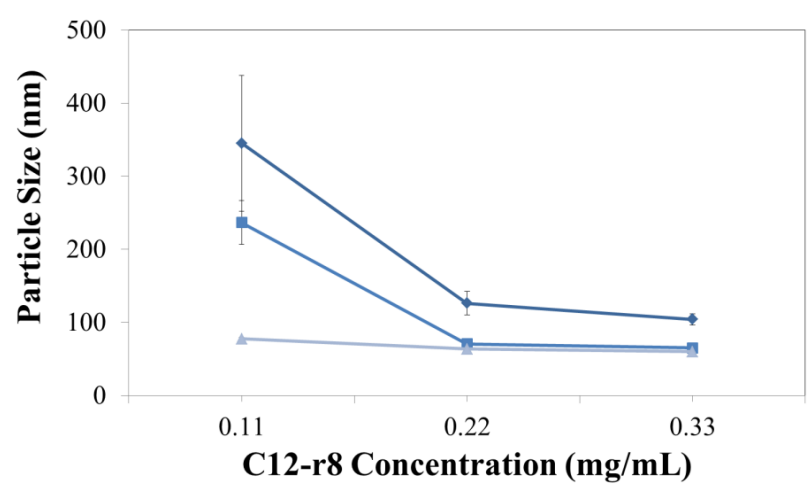

C

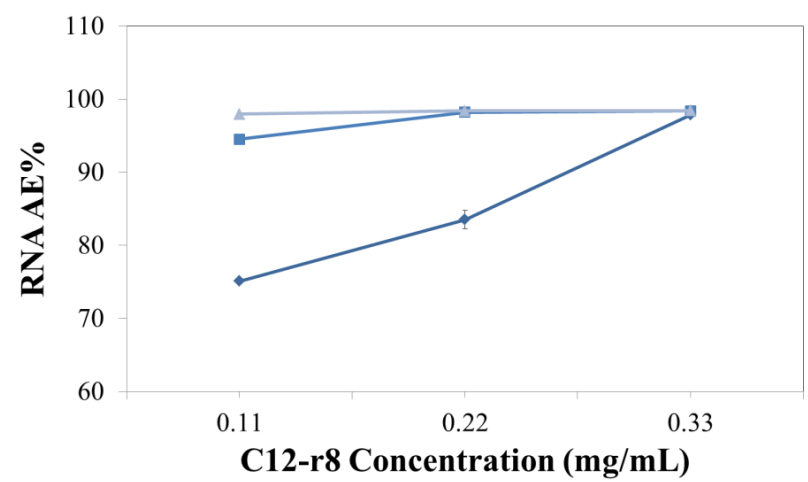

B

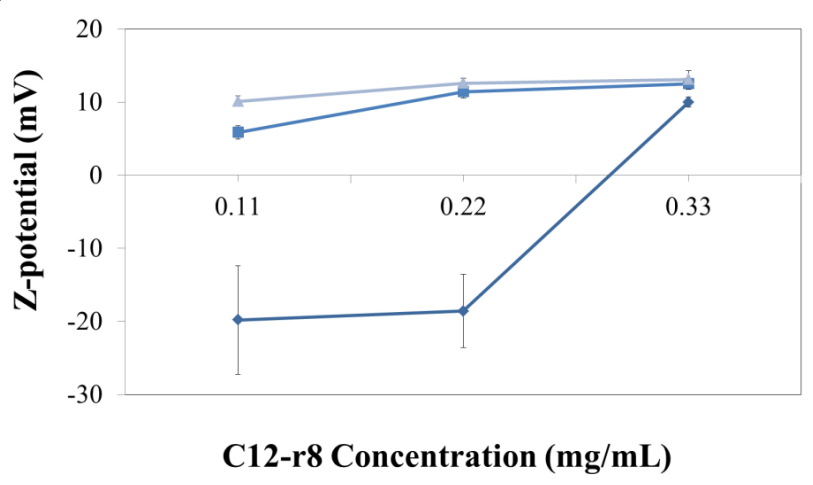

$\rightarrow$ FRR of RNA:C12-r8 $=2: 1$

$\rightarrow-F R R$ of RNA:C12-r8 $=2: 2$

$\rightarrow$ FRR of RNA:C12-r8 $=2: 3$

D

\begin{tabular}{c|c|c|c|c}
\hline Nanocomplexes & Av. Diam. (nm) & PDI & Z-pot (mV) & $\begin{array}{c}\text { A.E. } \\
(\%)\end{array}$ \\
\hline PEG-PGA enveloped ENCPs & $104 \pm 7$ & 0.11 & $+7 \pm 1$ & $\sim 100$ \\
\hline HA enveloped ENCPs & $87 \pm 9$ & 0.13 & $-27 \pm 4$ & $\sim 100$ \\
\hline
\end{tabular}

Figure 6. (A) Particle size, (B) Z-potential and (C) RNA AE\% of microfluidics produced non-coated nanocomplexes (NCPs) at different C12r8:tRNA flow rate ratio (FRR) and different C12-r8 concentrations (mean $\pm \mathrm{SD} ; \mathrm{n}=3$ ). (D) Physicochemical properties of microfluidics produced enveloped nanocomplexes (ENCPs) with C12-r8:tRNA charge ratio of $4: 1($ mean $\pm S D ; n=3)$. 
To generate enveloped ENCPs by microfluidics, the dispersion of the previously prepared C12-r8 - RNA nanocomplexes and an aqueous solution of the polymeric coating were added, in a second step, to the respective channels of the cartridge and were rapidly mixed under a flow rate of $8 \mathrm{ml} / \mathrm{min}$ (flow rate ratios between the two channels 2:1). The microfluidics prepared ENCPs exhibited similar properties with the ones produced by the bulk method, indicating the possibility to prepare the formulation in a completely reproducible, user-independent and scalable manner (Fig. 6D). ENCPs were also prepared using miR-132 mimic, a therapeutic miRNA mimic (or a non-specific/scramble miRNA oligonucleotide), instead of the model RNA molecule, following the same methodology, and showed similar characteristics.

\subsection{In vitro cellular uptake}

In order to assess the efficacy of the ENCPs technology as intracellular RNA delivery carriers, we studied their interaction with $\mathrm{CHO}$ cells following 4-hour incubation at $37^{\circ} \mathrm{C}$. This study was performed for miR-132 loaded nanocarriers. Free miR-132 complexed with RNAiMAX lipofectamine was used as a control. The miRNA was isolated at the end of the study and the amount of miR-132 internalized by the cells in each case was quantitatively analyzed by semi-quantitative PCR. The results in Fig. 7, showed a dramatically high RNA internalization when administered associated to HA ENCPs $(\sim 11,000$-fold change compared to endogenous miR-132) or PEG-PGA ENCPs ( 14,000-fold change to endogenous miR-132). More importantly, the cellular internalization of the miR-132 in the case of the ENCPs markedly exceeded that of the commercial lipofection reagent RNAiMAX ( $<<0.0001$ for PEG-PGA ENCPs and $p=0.0004$ for the HA ENCPs, Fig. 7), showing the capacity of these systems to induce cellular uptake. This property can be directly associated with the cellular internalization properties of the associated CPP (C12-r8).[21] The slightly greater cellular uptake achieved for the PEG-PGA ENCPs as compared to that of HA ENCPs could be simply explained by the smaller sizes and the neutral charge that the ENCPs exhibited when coated with PEG-PGA versus the negative HA. Functional validation of the cellular uptake of miR-132 was further assessed in vivo, as described below. 


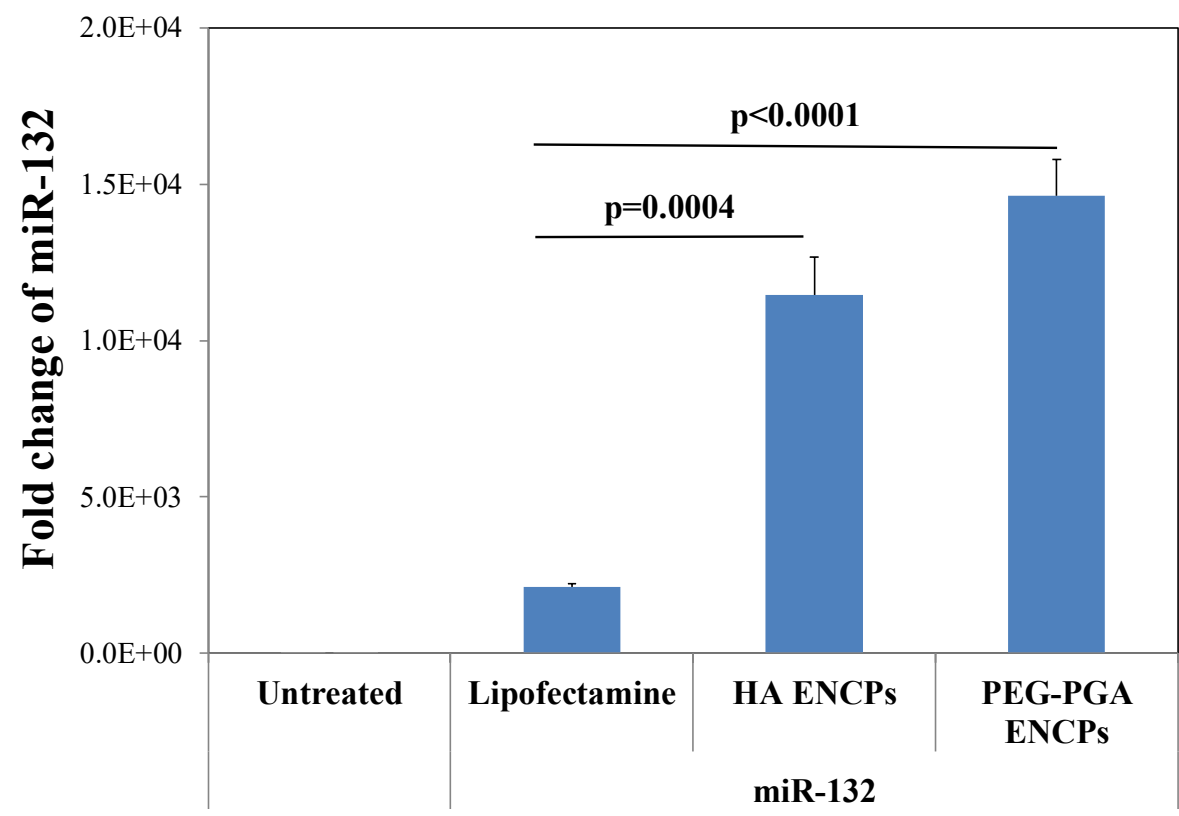

Figure 7. Semi-quantitative real-time PCR of miR-132 uptake in $\mathrm{CHO}$ cells following 4-hour incubation at $37^{\circ} \mathrm{C}$ with free miR-132 mimic, miR-132 mimic loaded HA ENCPs and PEG-PGA ENCPs.

\subsection{In vivo brain distribution and efficacy following N-to-B administration}

Encouraged by the highly positive in vitro results, we evaluated the potential of the ENCPs in a more physiologically relevant in vivo setting. A growing body of evidence has indicated that miRNAs may serve as powerful targets for therapeutic interventions against neurodegenerative diseases, like Alzheimer's disease (AD) $[28,30,32,42]$. As an example, recently published studies demonstrated that the local delivery of miR132 mimics enclosed in viral vectors in the hippocampus, led to the parcial restoration of memory function and tau metabolism in AD preclinical models $[34,43]$. Based on this, our goal was to prove that the ENCPs can deliver therapeutic miRNA molecules in vivo to the brain and specifically to the hippocampus, the area of the brain involved with memory formation and one of the first areas affected in Alzheimer's disease [44]. To that end, we administered intranasally miR-132 mimic included in ENCPs to an AD mouse model and we measured the levels of the miR-132 in three different brain areas; olfactory bulb, hippocampus and posterior cortex, using semi quantitative real-time PCR (Fig. 8A). The areas were selected in order to represent brain areas of interest, moving from anterior to posterior areas. For this study, we employed only the PEG-PGA ENCPs since based on the previously discussed results, the PEG-PGA ENCPs showed improved physicochemical characteristics and cellular uptake, compared to the HA enveloped ones. The results confirmed that the therapeutic miRNA mimics were effectively delivered to the hippocampus following the N-to-B administration of the miR-132 loaded ENCPs, leading to a significant $(\mathrm{p}=0.01)$ increase of the endogenous levels of miR-132 at 24 hours post administration (Fig. 8B). 


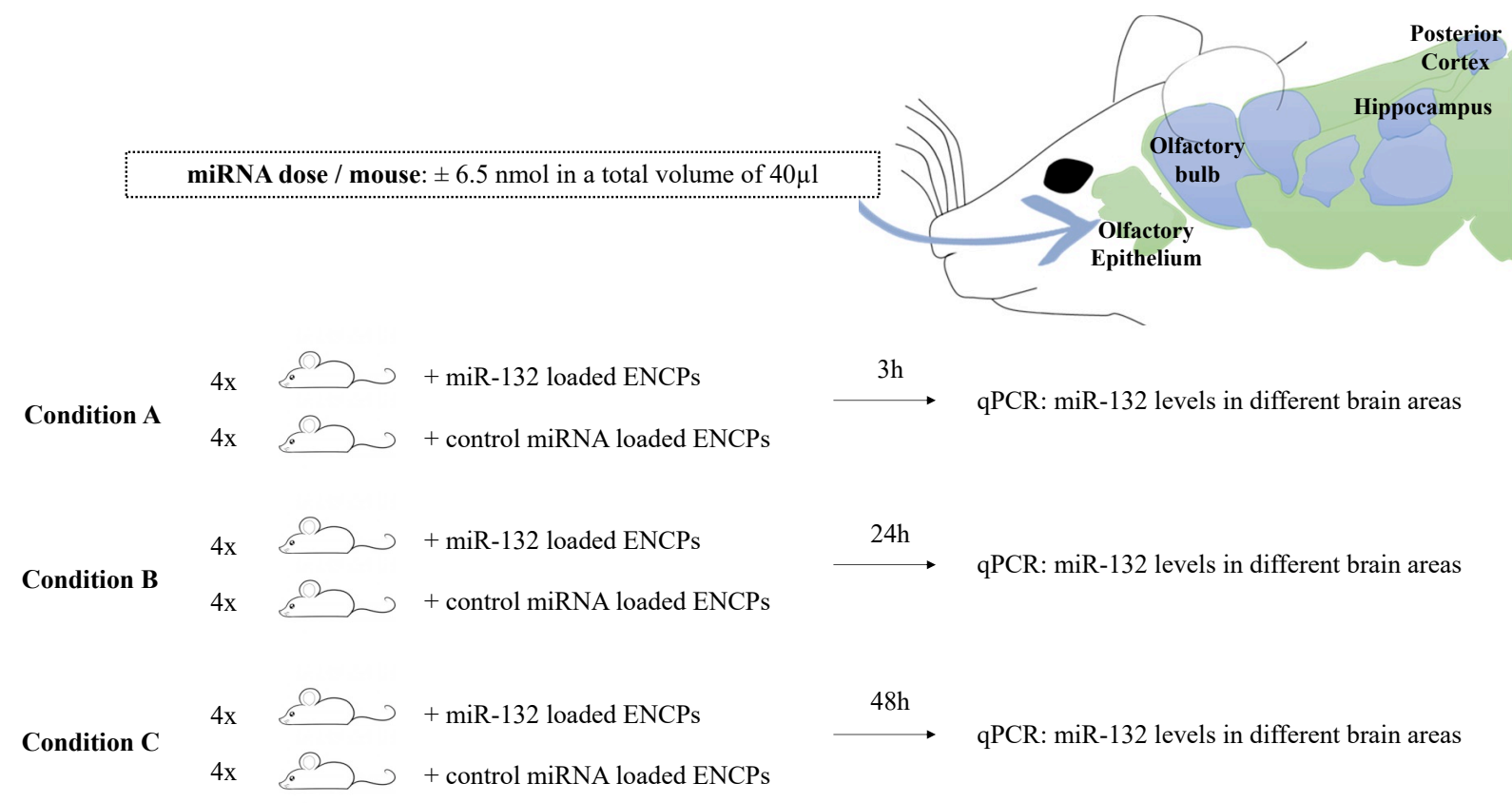

B

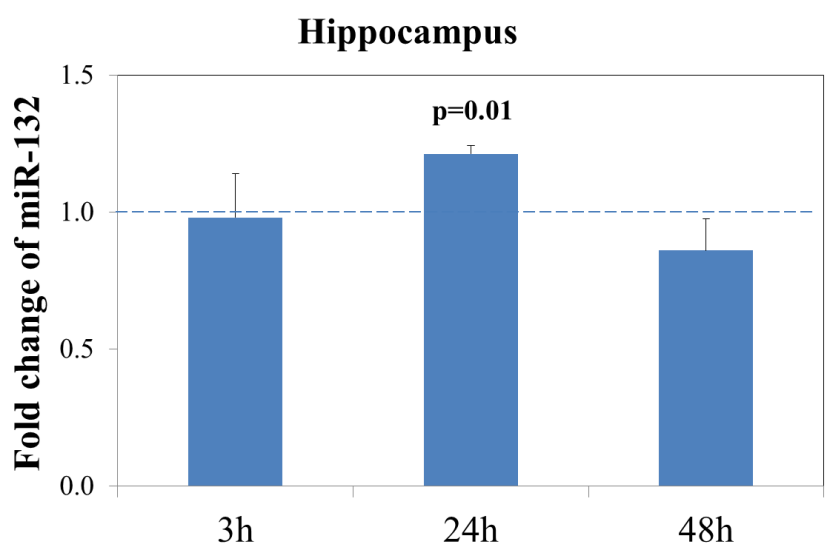

Figure 8. (A) Experimental scheme of N-to-B administration of PEG-PGA ENCPs in 11-month old mice in order to study the biodistribution of intranasally dosed miR-132. (B) Semi-quantitative PCR results of miR-132 levels in the olfactory bulb, hippocampus and posterior cortex of miR-132 ENCPs treated mice in comparison with control-dosed animals (scramble miRNA) at 3, 24 and $48 \mathrm{~h}$ post dose.

Our ultimate goal, however, was to show that the successfully delivered miR-132 mimics could mediate a therapeutic effect. It is generally known that miRNAs act as regulators of several signaling pathways underlying $\mathrm{AD}$, through complex mechanisms $[42,45,46]$. miR-132, specifically, is considered a master regulator in $\mathrm{AD}$ with strong neuroprotective activity, whereas its downregulation is strongly associated with AD pathology [34]. Numerous miR-132 target messenger RNAs (mRNAs) have been identified in literature as mediators of these effects $[47,48]$. For that reason, APP ${ }^{\mathrm{NL}-\mathrm{G}-\mathrm{F}}$ mice received a total miR-132 dose of $15 \mathrm{nmol}$ per mouse in 3 intranasal doses ( $2 \mathrm{~h}$ intervals), according to the experimental scheme described in Fig. 9A. 
Control mice received negative control miRNA loaded ENCPs. Twelve hours after the last dosing, the animals were sacrificed by cervical dislocation and their hippocampus levels of mRNA levels of miR-132 targets were assessed by semi-quantitative real-time PCR analysis, according to the protocol described above.

$\mathbf{A}$

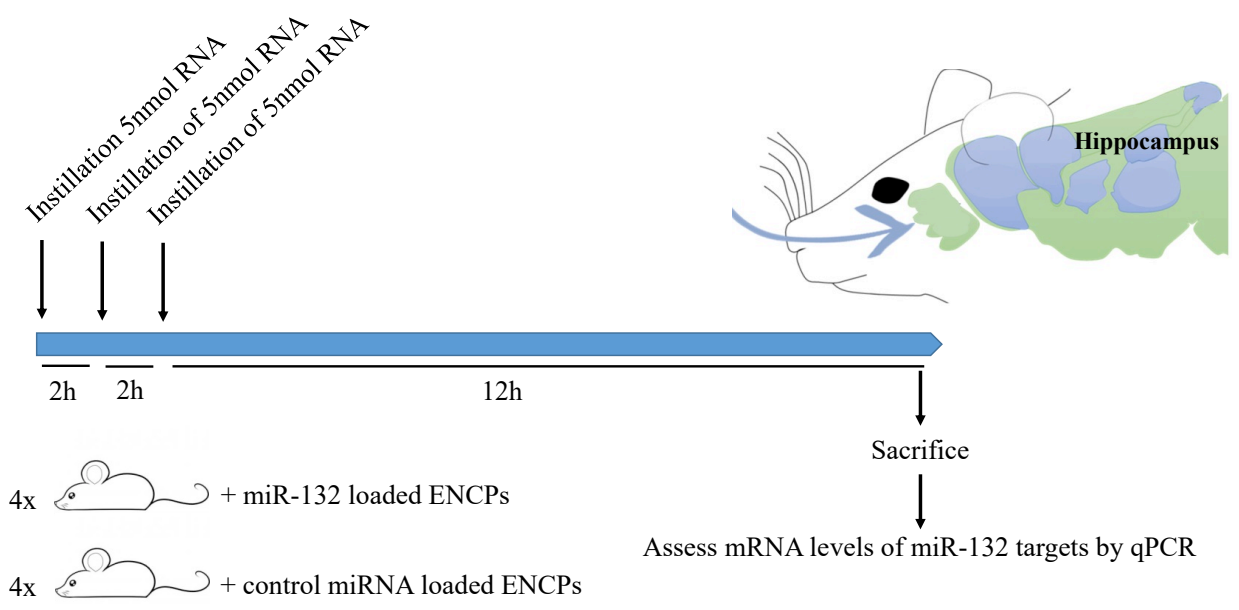

B
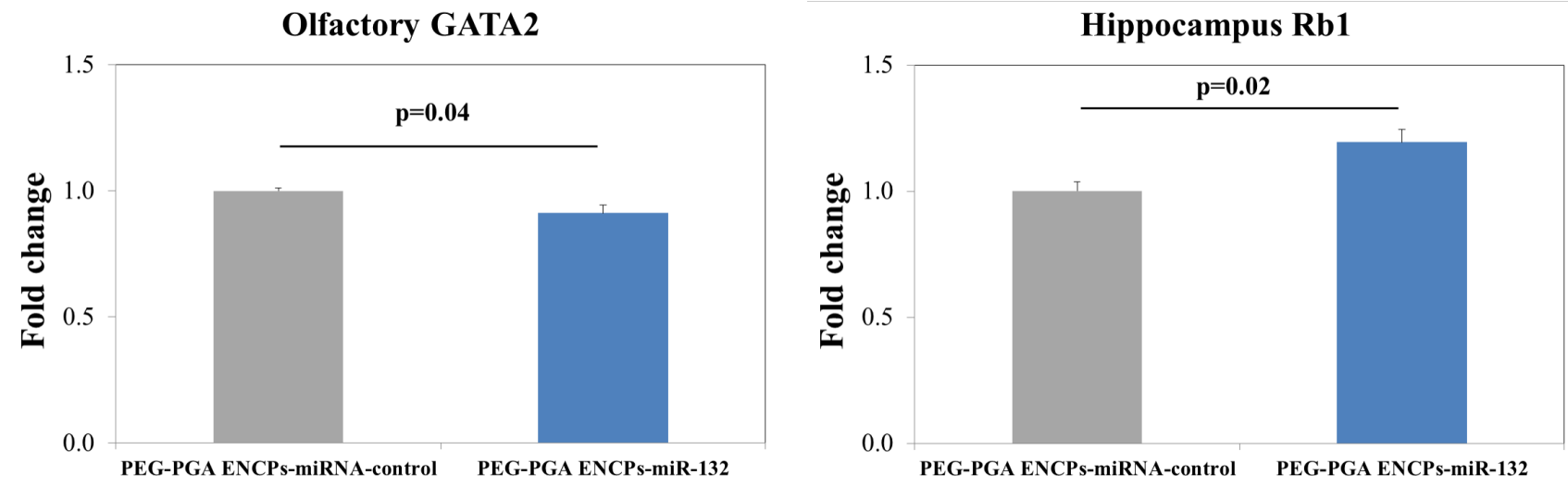

Figure 9. (A) Experimental scheme of miR-132 mimic intranasal (IN) dosing pattern in AD mouse model. (B) Semiquantitative PCR of miR-132 mRNA targets (GATA2 and RB1) in the hippocampus of miR-132 ENCPs-treated mice at 12 hours after the last dose compared to animals dosed with the negative control oligonucleotide loaded ENCPs.

As shown in Fig. 9B, the N-to-B administration of miR-132 mimic loaded ENCPs in AD mouse model could successfully increase the levels of the miR-132 in the hippocampus area of the brain when compared to the endogenous miRNA levels, which appeared to significantly affect the expression of two predicted mRNA targets (Targetscan Mouse, Release 7.1) that play a role in cell-cycle regulation. Results showed a $10 \%$ decrease in the levels of GATA2 mRNA at the olfactory bulb and a 20\% increase in retinoblastoma protein (Rb1) mRNA levels at the hippocampus (Fig. 9B). GATA2 is a transcription factor with a major role in development of the mouse brain [49]. Its overexpression has been associated with several diseases (i.e. 
leukemia, cancer, neuronal differentiation and depressive behaviors) [50]. On the other hand, Rb1 is a tumor suppressor retinoblastoma protein that regulates neuronal cell survival and has been implicated in the regulation of gene expression in $\mathrm{AD}[51,52]$. According to a recent study, $\mathrm{Rb} 1$ is one of the principal targets of the miRNAs upregulated during AD [53]. Altering the levels of two mRNA targets in two different areas of the CNS, implies that the miR-132 was delivered successfully in its active form with the help of the ENCPs. These results indicate that the therapeutic effect of miR-132 could be possibly mediated by multiple mRNA targets and probably more complex pathways than the ones studied here.

\section{Conclusions}

Here we describe a new nanotechnology that allows the delivery of miRNA from the nose directly to the brain as a potential therapeutic approach in Alzheimer's disease. This system was based on the formation of electrostatically driven nanocomplexes between a hydrophobic derivative of octaarginine (C12-r8), and the RNA of interest, and their subsequent envelopment with protective biopolymers. The results show the capacity of the nanocarrier to overcome significant challenges, such as (1) bypassing the BBB into the brain, (2) reaching the hippocampus, a brain area critical for learning and memory, and (3) upregulating miR-132 levels with the subsequent amelioration of its function. These findings demonstrate that nose-to-brain RNAi delivery holds great potential against neurodegenerative diseases. This route of administration, however, is still relatively new and not fully explored. Understanding in depth the involved pathways will allow us to design carriers capable of enhancing selective delivery to specific brain areas, and to develop tailor-made drug therapies for different neurological disorders.

\section{Acknowledgements}

The work was supported by the European B-Smart Consortium, which received funding from the European Union's Horizon 2020 research and innovation programme under grant agreement No 721058.

\section{Conflict of interest}

The authors declare that they have no conflict of interest.

\section{Appendix A. Supplementary data}

Supplementary data related to this article can be found at https://data.mendeley.com/datasets/sjdc343x3v/draft?a=89af0a93-3500-4134-8d02-ad6e46446ef9. 


\section{References}

1. Wold health organization (WHO) [Internet]. [cited 2017 Mar 17]. Available from: http://www.who.int

2. Alzheimers.net [Internet]. http://www.alzheimers.net/. [cited 2017 Mar 17]. Available from: http://www.alzheimers.net/

3. Zhao W, Hou X, Vick OG, Dong Y. RNA delivery biomaterials for the treatment of genetic and rare diseases. Biomaterials [Internet]. 2019;217(April):119291. Available from:

https://doi.org/10.1016/j.biomaterials.2019.119291

4. Pardridge WM. shRNA and siRNA delivery to the brain. Adv Drug Deliv Rev. 2007;59(2-3):141-52.

5. Juliano RL. The delivery of therapeutic oligonucleotides. Nucleic Acids Res. 2016;44(14):6518-48.

6. Dowdy SF. Overcoming cellular barriers for RNA therapeutics. Nat Biotechnol. 2017;35(3):222-9.

7. Khorkova O, Wahlestedt C. Oligonucleotide therapies for disorders of the nervous system. Nat Biotechnol. 2017;35(3):249-63.

8. Zheng M, Tao W, Zou Y, Farokhzad OC, Shi B. Nanotechnology-Based Strategies for siRNA Brain Delivery for Disease Therapy. Trends Biotechnol [Internet]. 2018;xx:1-14. Available from: http://dx.doi.org/10.1016/j.tibtech.2018.01.006

9. Kim I, Kim S, Lee J. Gene Knockdown in the Olfactory Bulb, Amygdala, and Hypothalamus by Intranasal siRNA Administration. Korean J Anat. 2009;42(4):285-92.

10. Bortolozzi A, Castãé A, Semakova J, Santana N, Alvarado G, Cortés R, et al. Selective siRNAmediated suppression of 5-HT1A autoreceptors evokes strong anti-depressant-like effects. Mol Psychiatry. 2012;17(6):612-23.

11. Renner DB, Frey WH, Hanson LR. Intranasal delivery of siRNA to the olfactory bulbs of mice via the olfactory nerve pathway. Neurosci Lett. 2012;513(2):193-7.

12. Mistry A, Stolnik S, Illum L. Nanoparticles for direct nose-to-brain delivery of drugs. Int J Pharm. 2009;379(1-2):146-57.

13. Samaridou E, Alonso MJ. Nose-to-brain peptide delivery - The potential of nanotechnology. 
Bioorganic Med Chem [Internet]. 2017;pii: S0968(17):31727-3. Available from:

https://doi.org/10.1016/j.bmc.2017.11.001

14. Malhotra M, Tomaro-Duchesneau C, Saha S, Prakash S. Intranasal siRNA Delivery to the Brain by TAT/MGF Tagged PEGylated Chitosan Nanoparticles. J Pharm [Internet]. 2013;2013:1-10. Available from:

http://dx.doi.org/10.1155/2013/812387\%5Cnhttp://www.hindawi.com/journals/jphar/2013/812387/

15. Kanazawa T, Akiyama F, Kakizaki S, Takashima Y, Seta Y. Delivery of siRNA to the brain using a combination of nose-to-brain delivery and cell-penetrating peptide-modified nano-micelles.

Biomaterials [Internet]. 2013;34(36):9220-6. Available from:

http://dx.doi.org/10.1016/j.biomaterials.2013.08.036

16. Kanazawa T, Morisaki K, Suzuki S, Takashima Y. Prolongation of life in rats with malignant glioma by intranasal siRNA/drug codelivery to the brain with cell-penetrating peptide-modified micelles. Mol Pharm. 2014;11(5):1471-8.

17. Kanazawa T. Brain delivery of small interfering ribonucleic acid and drugs through intranasal administration with nano-sized polymer micelles. Med Devices Evid Res. 2015;8:57-64.

18. Yadav S, Gandham SK, Panicucci R, Amiji MM. Intranasal Brain Delivery of Cationic Nanoemulsion-Encapsulated TNF $\alpha$ siRNA in Prevention of Experimental Neuroinflammation. Nanomedicine. 2016;12(4):987-1002.

19. Rodriguez M, Lapierre J, Ojha CR, Kaushik A, Batrakova E, Kashanchi F, et al. Intranasal drug delivery of small interfering RNA targeting Beclin1 encapsulated with polyethylenimine (PEI) in mouse brain to achieve HIV attenuation. Sci Rep. 2017;7(1):1-10.

20. Rassu G, Soddu E, Posadino AM, Pintus G, Sarmento B, Giunchedi P, et al. Nose-to-brain delivery of BACE1 siRNA loaded in solid lipid nanoparticles for Alzheimer's therapy. Colloids Surfaces B Biointerfaces [Internet]. 2017;152:296-301. Available from: http://dx.doi.org/10.1016/j.colsurfb.2017.01.031

21. Said Hassane F, Saleh AF, Abes R, Gait MJ, Lebleu B. Cell penetrating peptides: Overview and applications to the delivery of oligonucleotides. Cell Mol Life Sci. 2010;67(5):715-26.

22. Futaki S, Ohashi W, Suzuki T, Niwa M, Tanaka S, Ueda K, et al. Stearylated arginine-rich peptides: A 
new class of transfection systems. Bioconjug Chem. 2001;12(6):1005-11.

23. Khalil IA, Futaki S, Niwa M, Baba Y, Kaji N, Kamiya H, et al. Mechanism of improved gene transfer by the N-terminal stearylation of octaarginine: Enhanced cellular association by hydrophobic core formation. Gene Ther. 2004;11(7):636-44.

24. Li Y, Li Y, Wang X, Lee RJ, Teng L. Fatty acid modified octa-arginine for delivery of siRNA. Int J Pharm. 2015;495(1):527-35.

25. Kanazawa T, Kaneko M, Niide T, Akiyama F, Kakizaki S, Ibaraki H, et al. Enhancement of nose-tobrain delivery of hydrophilic macromolecules with stearate- or polyethylene glycol-modified argininerich peptide. Int J Pharm [Internet]. 2017;530(1-2):195-200. Available from: http://dx.doi.org/10.1016/j.ijpharm.2017.07.077

26. Belliveau NM, Huft J, Lin PJ, Chen S, Leung AK, Leaver TJ, et al. Microfluidic synthesis of highly potent limit-size lipid nanoparticles for in vivo delivery of siRNA. Mol Ther - Nucleic Acids. 2012;1:1-9.

27. Nilsson P, Saito T, Saido TC. New mouse model of Alzheimer's. ACS Chem Neurosci. 2014;5(7):499-502.

28. Salta E, Sierksma A, Vanden Eynden E, De Strooper B. miR-132 loss de-represses ITPKB and aggravates amyloid and TAU pathology in Alzheimer's brain. EMBO Mol Med [Internet]. 2016;8(9):1005-18. Available from: http://embomolmed.embopress.org/lookup/doi/10.15252/emmm.201606520

29. Livak KJ, Schmittgen TD. Analysis of relative gene expression data using real-time quantitative PCR and the 2- $\Delta \Delta \mathrm{CT}$ method. Methods. 2001;25(4):402-8.

30. Wood H. MicroRNA-132 — master regulator of neuronal health? Nat Rev Neurol [Internet]. 2018;132:41582. Available from: http://dx.doi.org/10.1038/s41582-018-0049-0

31. Smith PY, Hernandez-Rapp J, Jolivette F, Lecours C, Bisht K, Goupil C, et al. MiR-132/212 deficiency impairs tau metabolism and promotes pathological aggregation in vivo. Hum Mol Genet. 2015;24(23):6721-35.

32. Hernandez-Rapp J, Rainone S, Goupil C, Dorval V, Smith PY, Saint-Pierre M, et al. MicroRNA132/212 deficiency enhances $A \beta$ production and senile plaque deposition in Alzheimer's disease triple 
transgenic mice. Sci Rep [Internet]. 2016;6(June):1-11. Available from:

http://dx.doi.org/10.1038/srep30953

33. Salta E, De Strooper B. MicroRNA-132: A key noncoding RNA operating in the cellular phase of Alzheimer's disease. FASEB J. 2017;31(2):424-33.

34. El Fatimy R, Li S, Chen Z, Mushannen T, Gongala S, Wei Z, et al. MicroRNA-132 provides neuroprotection for tauopathies via multiple signaling pathways. Acta Neuropathol [Internet]. 2018;119. Available from: https://doi.org/10.1007/s00401-018-1880-5

35. Zhang Y, Köllmer M, Buhrman JS, Tang MY, Richard A. Gemeinhart. Arginine-rich, Cell Penetrating Peptide-anti-microRNA Complexes Decrease Glioblastoma Migration Potential. Peptides. 2014;58:83-90.

36. Li Y, Li Y, Wang X, Lee RJ, Teng L. Fatty acid modified octa-arginine for delivery of siRNA. Int J Pharm. 2015;495(1):527-35.

37. Blank A, Dekker CA. Ribonucleases of Human Serum, Urine, Cerebrospinal Fluid, and Leukocytes. Activity Staining following Electrophoresis in Sodium Dodecyl Sulfate-Polyacrylamide Gels. Biochemistry. 1981;20(8):2261-7.

38. Raines RT. Ribonuclease A. Chem Rev [Internet]. 1998;98(3):1045-66. Available from: http://pubs.acs.org/doi/abs/10.1021/cr960427h

39. Valencia PM, Farokhzad OC, Karnik R, Langer R. Microfluidic technologies for accelerating the clinical translation of nanoparticles. Nat Nanotechnol. 2012;7(10):623-629.

40. Stroock AD, Dertinger SKW, Ajdari A, Mezić I, Stone HA, Whitesides GM. Chaotic mixer for microchannels. Science (80- ). 2002;295(5555):647-51.

41. Garg S, Heuck G, Ip S, Ramsay E. Microfluidics: a transformational tool for nanomedicine development and production. J Drug Target. 2016;24(9):821-35.

42. Shaik MM, Tamargo IA, Abubakar MB, Kamal MA, Greig NH, Gan SH. The role of microRNAs in Alzheimer's disease and their therapeutic potentials. Genes (Basel). 2018;9(4).

43. Dong J, Liu Y, Zhan Z, Wang X. MicroRNA-132 is associated with the cognition improvement following voluntary exercise in SAMP8 mice. Brain Res Bull [Internet]. 2018;140(April):80-7. 
Available from: https://doi.org/10.1016/j.brainresbull.2018.04.007

44. Halliday G. Pathology and hippocampal atrophy in Alzheimer's disease. Lancet Neurol [Internet]. 2017;16(11):862-4. Available from: http://dx.doi.org/10.1016/S1474-4422(17)30343-5

45. Karnati HK, Panigrahi MK, Gutti RK, Greig NH, Tamargo IA. miRNAs: Key Players in Neurodegenerative Disorders and Epilepsy. J Alzheimer's Dis [Internet]. 2015 Oct 1;48(3):563-80. Available from: http://www.medra.org/servlet/aliasResolver?alias=iospress\&doi=10.3233/JAD150395

46. Femminella GD, Ferrara N, Rengo G. The emerging role of microRNAs in Alzheimer's disease. Front Physiol. 2015;6(February):1-5.

47. Miller BH, Zeier Z, Xi L, Lanz TA, Deng S, Strathmann J, et al. MicroRNA-132 dysregulation in schizophrenia has implications for both neurodevelopment and adult brain function. Proc Natl Acad Sci. 2012;109(8):3125-30.

48. Park JK, Henry JC, Jiang J, Esau C, Gusev Y, Lerner MR, et al. MiR-132 and miR-212 are increased in pancreatic cancer and target the retinoblastoma tumor suppressor. Biochem Biophys Res Commun. 2011;406(4):518-23.

49. El Wakil A, Francius C, Wolff A, Pleau-Varet J, Nardelli J. The GATA2 transcription factor negatively regulates the proliferation of neuronal progenitors. Development. 2006;133(11):2155-65.

50. Choi M, Wang SE, Ko SY, Kang HJ, Chae SY, Lee SH, et al. Overexpression of human GATA-1 and GATA-2 interferes with spine formation and produces depressive behavior in rats. PLoS One. 2014;9(10):1-10.

51. Andrusiak MG, Vandenbosch R, Park DS, Slack RS. The retinoblastoma protein is essential for survival of postmitotic neurons. J Neurosci. 2012;32(42):14809-14.

52. Ranganathan S, Scudiere S, Bowser R. Hyperphosphorylation of the retinoblastoma gene product and altered subcellular distribution of E2F-1 during Alzheimer's disease and amyotrophic lateral sclerosis. J Alzheimer's Dis. 2001;3(4):377-85.

53. Absalon S, Kochanek DM, Raghavan V, Krichevsky AM. MiR-26b, upregulated in Alzheimer's disease, activates cell cycle entry, Tau-phosphorylation, and apoptosis in postmitotic neurons. J Neurosci. 2013;33(37):14645-59. 